Published in final edited form as:

Neurobiol Dis. 2007 December ; 28(3): 276-285. doi:10.1016/j.nbd.2007.07.022.

\title{
Mouse Models of Diabetic Neuropathy
}

\author{
Kelli A. Sullivan ${ }^{1}$, John M. Hayes ${ }^{1}$, Timothy D. Wiggin ${ }^{1}$, Carey Backus ${ }^{1}$, Sang Su Oh${ }^{1}$, \\ Stephen I. Lentz ${ }^{3}$, Frank Brosius III ${ }^{2}$, and Eva L. Feldman ${ }^{1, \S}$ \\ ${ }^{1}$ Department of Neurology, University of Michigan, University of Michigan, Ann Arbor, Michigan \\ USA
}

2 Department of Internal Medicine, Division of Nephrology, University of Michigan, University of Michigan, Ann Arbor, Michigan USA

${ }^{3}$ Department of Internal Medicine, Division of Endocrinology and Metabolism, University of Michigan, Ann Arbor, Michigan USA

\begin{abstract}
Diabetic neuropathy (DN) is a debilitating complication of type 1 and type 2 diabetes. Rodent models of DN do not fully replicate the pathology observed in human patients. We examined DN in streptozotocin (STZ)-induced [B6] and spontaneous type 1 diabetes [B6Ins2 ${ }^{\text {Akita] }}$ and spontaneous type 2 diabetes [B6-db/db, BKS-db/db]. DN was defined using the criteria of the Animal Models of Diabetic Complications Consortium (http://www.amdcc.org). Despite persistent hyperglycemia, the STZ-treated B6 and B6Ins2 ${ }^{\text {Akita }}$ mice were resistant to the development of DN. In contrast, DN developed in both type 2 diabetes models: the B6-db/db and BKS-db/db mice. The persistence of hyperglycemia and development of DN in the B6-db/db mice required an increased fat diet while the BKS-db/db mice developed severe DN and remained hyperglycemic on standard mouse chow. Our data support the hypothesis that genetic background and diet influence the development of DN and should be considered when developing new models of DN.
\end{abstract}

\section{Keywords}

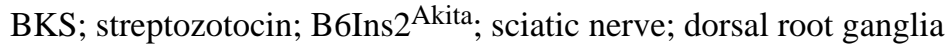

\section{INTRODUCTION}

Over twenty million Americans are diabetic and the incidence is increasing by $5 \%$ per year. The most common complication of diabetes is neuropathy (DN) which occurs in approximately $60 \%$ of diabetic patients (Vincent and Feldman, 2004). In the United States, DN is the leading cause of diabetes-related hospital admissions and nontraumatic amputations (Boulton et al., 2005) (http://www.diabetes.org).

There are no accepted treatments for DN beyond glucose control. In part, the lack of effective therapies stems from the lack of animal models of DN. The Animal Models of Diabetic Complications Consortium (AMDCC) was formed by the NIH to develop new

§Corresponding Author: Eva L. Feldman, M.D., Ph.D., University of Michigan, Department of Neurology, 5017 Basic Science Research Building (BSRB), 109 Zina Pitcher Road, Ann Arbor, MI 48109-2200, 734-763-7274 (phone), 734-763-7275 (fax), efeldman@umich.edu.

Publisher's Disclaimer: This is a PDF file of an unedited manuscript that has been accepted for publication. As a service to our customers we are providing this early version of the manuscript. The manuscript will undergo copyediting, typesetting, and review of the resulting proof before it is published in its final citable form. Please note that during the production process errors may be discovered which could affect the content, and all legal disclaimers that apply to the journal pertain. 
animal models of diabetic complications; its goal is to identify the most appropriate animal models to study the etiology, prevention and treatment of diabetic complications, including DN.

The most useful mouse model of DN should exhibit the key features present in human pathology (Feldman et al., 2003) including; 1) sensory loss, 2) electrophysiological measures of nerve impairment, and 3) anatomical evidence of nerve fiber loss. The AMDCC established a standardized set of protocols for phenotyping animal models of DN (http:// www.amdcc.org). Neuropathy phenotyping begins with evaluation of sensory loss by quantitative assessment of thermal sensitivity. Electrophysiological measures of nerve impairment are the "gold standard" for determining sensory and motor nerve function and include assessment of motor and sensory nerve conductions in the tail and sciatic nerve. Finally, analysis of the number of small fibers in the mouse footpad lends insight into function. Anatomical evidence of nerve fiber loss is measured by assessment of intraepidermal nerve fiber (IENF) density in the footpad.

The current study utilized AMDCC criteria to examine DN in 4 inbred strains of mice. Our goal was to identify mouse models that closely resemble neural changes present in patients with DN. We hypothesize that development of DN is multifactorial and is influenced by background strain and diet. We determined that the most robust model for DN was the $\mathrm{db} / \mathrm{db}$ mouse on the C57BLKS background. This model remained hyperglycemic without dietary intervention and developed progressive loss of sensory function, slowed nerve conductions and loss of intraepidermal nerve fibers. Our finding that the development of DN varies across mouse models of diabetes agrees with the recent report from the AMDCC Nephropathy Group (Qi et al., 2005).

\section{RESEARCH DESIGN AND METHODS}

\section{Mice}

Mice (Table 1) were purchased from Jackson Laboratories (Bar Harbor, Maine). Breeding colonies were established at the University of Michigan to provide the animals used in this study and were genotyped 4 weeks after birth. Mice were housed in a pathogen-free environment, with continuous access to food (see below) and water on a 12-hour light-dark schedule and were cared for following the University of Michigan Committee on the Care and Use of Animals guidelines.

\section{Induction or Onset of Diabetes}

In the following text, mice are referred to by their common names (Table 1). Following an overnight fast, 8 week old male C57BL/6J were injected i.p. with $55 \mathrm{mg} / \mathrm{kg}$ of streptozotocin (STZ, Sigma Aldrich, St. Louis, MO) dissolved in citrate buffer ( $\mathrm{pH}$ 5.5) for 5 days. Diabetes was defined as blood glucose over $200 \mathrm{mg} / \mathrm{dL}$. Diabetes was confirmed in heterozygous male B6Ins $2^{\text {Akita }}$ mice and male and female B6-db/db and BKS-db/db mice at 8 weeks of age. B6-db/db and B6- $\mathrm{db}^{+}$mice were maintained on either a synthetic diet (AIN-76A, 11.5\% kcal derived from fat, lacking phytoestrogens, Research Diets, New Brunswick, NJ) or an increased fat diet $(5008,17 \%$ kcal derived from fat, LabDiet, Purina Mills). All other mice were fed standard mouse chow (5001, 12\% kcal derived from fat, LabDiet, PMI Nutrition International, LLC, St. Louis MO). The diets were not irradiated or autoclaved.

Blood glucose levels were measured every 4 weeks to document the persistence and duration of diabetes. Following a $6 \mathrm{~h}$ fast, one drop of tail blood was analyzed using a standard glucometer (One Touch Profile, LIFESCAN, Inc. Milpitas, CA). At the end of the experimental period, glycated hemoglobin $(\mathrm{GHb})$ was measured using the Helena 
Laboratories Test Kit, Glyco-Tek Affinity Column Method. Analyses and procedures were performed in compliance with protocols established by the AMDCC (http:// www.amdcc.org).

\section{Sensory Testing, Tail Flick and Hind Paw Analgesia}

Mice were placed in an acrylic holder atop a tail flick analgesia meter (Model 336TG Life Sciences, Woodland Hills, CA) so that the tail was in contact with an adjustable red light emitter (range $60-170^{\circ} \mathrm{C}$ ). The time from activation of the beam to animal response was recorded electronically (Lee et al., 1990). Hind paw analgesia was measured using the same apparatus. The mice were placed in compartments on a warm $\left(32^{\circ} \mathrm{C}\right)$ glass plate and allowed to habituate for 10 minutes. The light source was maneuvered under the hind paw and the time of activation of the beam to the time of paw withdrawal was recorded (Lee et al., 1990). The light source was set at $25^{\circ} \mathrm{C}$ and the temperature increased to $70^{\circ} \mathrm{C}$ over the course of 10 seconds. A threshold of 10 seconds was applied to prevent injury to the mice.

\section{Nerve Conduction Studies}

Measures of nerve conduction velocity (NCV) were performed per our published protocols (Stevens et al., 1994;Stevens et al., 1996;Russell et al., 1999;Layton et al., 2004) and in compliance with protocols established by the AMDCC (http://www.amdcc.org).

Mice were anesthetized with 30/2.5 mg/kg ketamine/xylazine and body temperature was monitored with a dermal temperature probe and maintained at $34^{\circ} \mathrm{C}$ with a warming lamp. The needle electrodes were cleaned with $70 \%$ alcohol between animals to maintain pathogen-free status. The recording/stimulating electrodes in the tail were placed $30 \mathrm{~mm}$ apart. For the sciatic nerve the recording electrodes were placed in the dorsum of the foot and the stimulating electrodes at the knee and sciatic notch. For stimulation, the cathode was distal, the anode was placed along the length of the nerve, $5 \mathrm{~mm}$ from the cathode. The frequency band was inclusive of two, $10 \mathrm{~Hz}$ for muscle potential recordings and ten, $2 \mathrm{~Hz}$ for sensory potential recordings.

Tail sensory NCV (TSNCV) was an orthodromic measurement determined by stimulating the tail $30 \mathrm{~mm}$ proximal to recording electrodes on the tail. NCV was calculated by dividing the distance $(30 \mathrm{~mm}$ ) by the take-off latency (msec) of the sensory nerve action potential. Tail motor distal latency (TDML) was determined by stimulating the tail $30 \mathrm{~mm}$ distal to a recording electrode. Latency was measured from initial onset of the compound muscle action potential. Sciatic-tibial motor NCV (SMNCV) was determined by recording in the dorsum of the foot and stimulating with supramaximal stimulation first at the knee, then at the sciatic notch. Latencies were measured in each case from the initial onset of the compound muscle action potential. The sciatic-tibial motor NCV was calculated by dividing the distance between the cathode placements by the difference calculated by subtracting the motor distal latency at the knee from the sciatic notch.

\section{Tissue Harvest}

Tissues were harvested 24 weeks post-induction of diabetes. The mice were euthanized by sodium pentobarbital overdose. A blood sample $(50 \mathrm{uL})$ was collected for measurement of $\mathrm{GHb}$ (see above). Following intracardiac perfusion with PLP (2\% paraformaldehyde, lysine and sodium periodate in phosphate buffer, $0.1 \mathrm{M}, \mathrm{pH} 7.2$ ), dorsal root ganglia (DRG) were dissected and postfixed in fresh PLP overnight at $4^{\circ} \mathrm{C}$.

\section{Intraepidermal Nerve Fiber Density (IENF)}

Prior to perfusion, foot pads were collected from the plantar surface of the hind paw, immersed in Zamboni's fixative (2\% paraformaldehyde, $0.2 \%$ picric acid in $0.1 \mathrm{M}$ 
phosphate buffer) overnight at $4{ }^{\circ} \mathrm{C}$, rinsed in 5,10 and $20 \%$ sucrose in $0.1 \mathrm{M}$ sodium phosphate buffer, cryoembedded, sectioned $(30 \mu \mathrm{m})$ and processed for pan-axonal marker, PGP9.5, immunofluorescence (1:2000 Chemicon, Temecula, CA) (Polydefkis et al., 2001). Three images per sample were collected on an Olympus FluoView 500 confocal microscope using a 60 X 1.2 water immersion objective at a resolution of 800 X 600 pixels. The optical section thickness was $0.5 \mu \mathrm{m}$. Forty images per stack were flattened using MetaMorph (version 6.14) arithmetic option. The data are presented as the number of fibers per linear $\mathrm{mm}$ of epidermis (Christianson et al., 2003a).

\section{Fragmentation of Nuclear DNA}

TdT mediated dUTP-biotin nick end labeling (TUNEL) staining was used to detect damaged DNA (Russell et al., 2002). DRG were cryoembedded and $10 \mu \mathrm{m}$ sections collected onto SuperFrost Plus slides (Fisher Scientific, Pittsburgh, PA). Samples were labeled with digoxygenin-dUTP and detected with biotin conjugated anti-digoxygenin antibody followed by avidin-horseradish peroxidase according to the manufacturer's instructions (Intergen, Gaithersburg, MD). The chromogen was developed with 3'3-diaminobenzidine in the presence of $\mathrm{H}_{2} \mathrm{O}_{2}$.

\section{Nitrotyrosine (NT) Immunofluorescence}

Post-translational modification of proteins via nitration of tyrosine residues (3-nitrotyrosine, NO2-Tyr) serve as a marker of reactive nitrogen species (RNS). Nitrated proteins are the result of oxidative and nitrosative stress and were identified using anti-nitrotyrosine (antiNT) immunofluorescence (Ilnytska et al., 2006). DRG sections were thawed on a warming plate, incubated in rabbit anti-NT (1:500, Upstate Biotechnology, Lake Placid, NY) followed by goat anti-rabbit IgG (AlexaFluor 594, Invitrogen, Carlsbad, CA) (Sullivan et al., 1995; Cheng et al., 1996). Tissue sections were viewed with a 40X phase objective on a Nikon Diaphot 200 inverted fluorescent microscope. The fluorescent signal was visualized with $488 \mathrm{~nm}$ excitation and 505-525 nm emission filters. Digital images were captured with a Hamamatsu ORCA ER camera controlled by Simple PCI (Compix Inc.). Exposure times were adjusted to minimize pixel saturation and identical settings were used to capture all images. Individual images were analyzed by pixel intensity values ranging between 0 and 255 (MetaMorph, version 6.1r5, Universal Imaging Corporation, Downington, PA).

\section{RESULTS}

\section{Metabolic Parameters}

Pancreatic beta cell destruction with STZ is a commonly used model of type 1 diabetes. This strategy was employed in the C57BL/6J strain of mice. STZ-treated C57BL/6J developed significantly higher levels of fasting blood glucose than vehicle injected mice. Elevated blood glucose levels were consistent throughout the experimental period and reflected by elevated GHb measured at the end of 24 weeks (Table 2). C57BL/6J STZ-treated mice lost weight compared to the non-treated control mice (Table 2). The B6Ins $2^{\text {Akita }}$ mouse is a model of spontaneous type 1 diabetes on the C57BL/6J background. These animals develop hyperglycemia at approximately 4 weeks of age. At the end of 24 weeks, fasting blood glucose and $\mathrm{GHb}$ were significantly elevated in diabetic B6Ins $2^{\text {Akita }}$ mice compared to nondiabetic B6Ins2 ${ }^{\mathrm{WT}}$ mice (Table 2). Weights in these animals, similar to the STZ model of diabetes, were decreased (Table 2).

The models of type 2 diabetes used in the current study include the B6-db/db, B6- $\mathrm{db}^{+}$mice and BKS-db/db, BKS- $\mathrm{db}^{+}$mice $\left[\mathrm{db}^{+}=\right.$nondiabetic, $\mathrm{db} / \mathrm{db}=$ diabetic for both genetic strains of mice]. Both B6-db/db and BKS-db/db mice develop hyperglycemia between 3-4 weeks of age (http://jaxmice.jax.org/). We previously established that B6-db/db mice revert to 
euglycemia if fed standard 5001 chow $(12 \%$ kcal derived from fat, data not shown, but reported on the AMDCC website, http://www.amdcc.org). To maintain hyperglycemia in the current study, the B6-db/db mice were fed one of two diets: the AIN-76A synthetic diet $(11.5 \% \mathrm{kcal}$ derived from fat) or the 5008 diet (17\% kcal derived from fat). At 24 weeks, diabetic $(\mathrm{db} / \mathrm{db})$ mice on both diets developed significantly elevated fasting glucose, $\mathrm{GHb}$ and body weights compared to their nondiabetic $\left(\mathrm{db}^{+}\right)$littermates (Table 2). However, the degree of hyperglycemia in mice fed the AIN-76A diet was more modest compared to animals fed the high fat $5008 \operatorname{diet}$ ( $\mathrm{GHb}$ of $7.3 \pm 0.27 \%$ versus $12.8 \pm 0.63 \%$, respectively).

Increased kcal derived from fat increases mortality in the BKS-db/db mice (Leiter et al., $1981)$; therefore, these animals were maintained on the standard chow diet $(5001,12 \% \mathrm{kcal}$ derived from fat). Hyperglycemia was confirmed at 8 weeks in these mice and was maintained for 24 weeks. Both fasting blood glucose and $\mathrm{GHb}$ were significantly elevated in the BKS-db/db mice compared to BKS- $\mathrm{db}^{+}$mice. The BKS-db/db mice were also obese and their weights were significantly greater than the BKS- $\mathrm{db}^{+}$mice (Table 2 ).

\section{Sensory Measures, Tail Flick and Hind Paw Analgesia}

Increased tail flick thresholds were not detected in either model of type 1 diabetes. STZtreated C57BL/6J mice did not develop sensory deficits despite significant hyperglycemia (Fig. 1A). In the diabetic B6Ins2 $2^{\text {Akita }}$ mice, sensory changes (tail flick and hind paw measurements) were modest but a statistically significant difference in hind paw sensory latency was detected at 24 weeks of hyperglycemia (nondiabetic $2.9 \pm 0.06$, diabetic $3.3 \pm$ 0.03, \#p< 0.02) (Fig. 1C).

Both the B6-db/db and BKS-db/db mice demonstrated elevated tail flick latencies indicating sensory loss. In the B6-db/db mice fed a high fat diet, tail flick latency was significantly elevated in the diabetic mice compared to the nondiabetic mice (nondiabetic $5.9 \pm 0.07 \mathrm{sec}$ and diabetic $9.7 \pm 0.09 \mathrm{sec},{ }^{*} \mathrm{p}<0.001$ ) (Fig. 1B) as was hind paw latency (nondiabetic 4.5 \pm 0.17 , diabetic $3.5 \pm 0.19,, \varphi p<0.002$, Fig. 1C). BKS-db/db mice also demonstrated significantly elevated latencies for tail flick (nondiabetic $4.8 \pm 0.14$ and diabetic $9.7 \pm 0.07$, *p $<0.001$ ) (Fig. 1B). Hind paw latencies were not performed on these animals due to the severity of their neuropathy.

\section{Nerve Conduction Studies and Intraepidermal Nerve Fiber Density (IENF)}

Nerve conduction velocities (NCV) were measured in the tail (tail sensory nerve conduction velocity, TSNCV, tail distal motor latency, TDML) and in the sciatic nerve (sciatic motor nerve conduction velocity, SMNCV). Despite an average fasting glucose of $466 \pm 7.4 \mathrm{mg} /$ $\mathrm{dL}$ and a GHb $12.4 \pm 0.29 \%$, the STZ-treated C57BL/6J did not develop significant changes in any measures of NCV (Fig. 2 thru 4). The B6Ins $2^{\text {Akita }}$ mice also retained significant hyperglycemia (average fasting glucose $584.6 \pm 3.2 \mathrm{mg} / \mathrm{dL}$ of and $\mathrm{GHb}$ of $15.0 \pm 0.37 \%$, ) but also demonstrated no significant changes in any measures of NCV (Figs. 2-4).

Both type 2 models demonstrate significant changes in NCV that were dependent on the degree of glycemia. The B6-db/db mice fed a synthetic diet developed modest hyperglycemia (average fasting glucose $170.3 \pm 13.4 \mathrm{mg} / \mathrm{dL}$ and $\mathrm{GHb}$ of $7.3 \pm 0.27 \%$,) with parallel modest changes in NCV. In addition, nerve conduction in the tail was slowed (TSNCV nondiabetic $25.4 \pm 0.2$, diabetic $22.1 \pm 0.4, \gamma \mathrm{p}<0.01$; TDML nondiabetic $2.7 \pm$ 0.07 , diabetic $3.3 \pm 0.09, \lambda p<0.05$ ) (Figs. 2 and 3); however, SMNCV was unaffected (Fig. 4). In the tail of B6-db/db mice on a high fat diet, TSNCV was significantly reduced (nondiabetic $24.4 \pm 0.7$, diabetic $15.6 \pm 0.9$, ${ }^{*} \mathrm{p}<0$. 001, Fig. 2) and TDML was increased (nondiabetic $2.4 \pm 0.09$, diabetic $3.8 \pm 0.2, \varphi \mathrm{p}<0.002$, Fig. 3 ). SMNCV was slowed by 
diabetes in these animals but did not reach statistical significance (nondiabetic $33.1 \pm 2.2$, diabetic $26.7 \pm 3.9$; Fig. 4).

The BKS-db/db mice demonstrated the most profound changes in NCV with decreased TSNCV (nondiabetic 23.8 \pm 0.2 , diabetic $17.4 \pm 0.3$, ${ }^{*} \mathrm{p}<0.001$, Fig. 2), increased TDML (nondiabetic $2.97 \pm 0.02$, diabetic $4.7 \pm 0.07$, $* \mathrm{p}<0.001$, Fig. 3 ), and decreased SMNCV (nondiabetic $38.8 \pm 0.8$, diabetic $26.7 \pm 1.2$, $\gamma \mathrm{p}<0.05$, Fig. 4 ). In parallel, BKS-db/db mice demonstrate significantly reduced IENF at 24 weeks post onset of diabetes $(\gamma p<0.01$, Fig. $5 \mathrm{~A}-\mathrm{C})$.

\section{Fragmentation of Nuclear DNA and Nitrotyrosine IHC}

Advanced measures of DN including TUNEL and NT IHC were only performed on the most robust model of DN, the BKS- $\mathrm{db} / \mathrm{db}$ and BKS- $\mathrm{db}^{+}$mice. Fragmented DNA is a marker of damaged DNA (Russell and Feldman, 1999) and is used in our laboratory to measure the effects of glucose toxicity in DRG neurons both in vitro (Russell and Feldman, 1999) and in vivo (Russell et al., 1999). An increase in the number of TUNEL positive sensory neurons was detected at 24 weeks in the DRG of BKS-db/db mice (Fig. 6). NT immunoreactivity localizes nitrated proteins and is a marker of oxidative/nitrosative stress (Ilnytska et al., 2006). An increase in the number and intensity of NT positive sensory neurons was detected at 24 weeks in the DRG of BKS-db/db mice $(\gamma p<0.01$, Fig. 6).

\section{DISCUSSION}

A relevant mouse model of DN must demonstrate key features of human disease including 1) loss of sensory function, 2) electrophysiological measures of nerve impairment, and 3) nerve fiber loss (Ad Hoc Panel on Endpoints for Diabetic Neuropathy Trials, 2001). The AMDCC established a standardized set of phenotyping protocols for DN in murine models of diabetes utilizing these criteria. Specifically, thermal sensitivity in the tail and hind paw, NCV and IENF density are used to determine if diabetic mouse models develop DN. In the current study, these measures were used to assess 4 mouse models of diabetes for the presence of DN. Our hypothesis was that the development of DN in mouse models would primarily depend on the level and duration of hyperglycemia and that commonly used inbred mouse strains would be equally susceptible to the development of DN.

\section{Models of Type 1 and 2 Diabetes}

In the current study, mouse models of both type 1 diabetes (STZ-treated C57BL/6J and spontaneous type 1 B6Ins2 $\left.{ }^{\text {Akita }}\right)$ and type 2 diabetes [(B6-db/db and BKS-db/db] were examined. Induction of diabetes with STZ is performed by a number of different methods including single injection or multiple doses over 3 to 5 days (Goss et al., 2002;Kennedy and Zochodne, 2000; Qi et al., 2005). These methods produce blood glucose levels in the range of 200 to over $500 \mathrm{mg} / \mathrm{dL}$ (Goss et al., 2002;Kennedy and Zochodne, 2000; Qi et al., 2005). In the current study, a 5 day course of STZ was administered to the C57BL/6J animals in accordance with current AMDCC protocols (http://www.amdcc.org). In agreement with previous reports of this model of type 1 diabetes, these mice became hyperglycemic and lost weight (Goss et al., 2002;Kennedy and Zochodne, 2000;Qi et al., 2005).

Heterozygous B6Ins2 ${ }^{\text {Akita }}$ mice (C57BL/6J background) express a spontaneous mutation in the Ins2 locus resulting in deficient insulin secretion and the development of type 1 diabetes (http://jaxmice.jax.org/). B6Ins2 $2^{\text {Akita }}$ mice develop impaired insulin secretion at 4 weeks of age with subsequent loss of pancreatic beta cells, hyperglycemia and concomitant weight loss (Yoshioka et al., 1997); however, they retain the ability to respond to exogenous insulin, a further indication of their usefulness in modeling type 1 diabetes (http:// 
jaxmice.jax.org/). This phenotype is more pronounced in male than female mice therefore only male B6Ins2 $2^{\text {Akita }}$ mice were examined in the current study. Both the STZ-treated C57BL/6J and the B6Ins2 $2^{\text {Akit }}$ mice were fed a standard chow diet and demonstrated significant and persistent hyperglycemia for 24 weeks. Both animal models showed no ill effects from their diabetes.

B6-db/db and BKS-db/db mice express a mutation of the leptin receptor and develop hyperglycemia and hyperphagia (http://jaxmice.jax.org/). In the B6-db/db mice, diet had a profound effect on the animals' metabolism. Previous studies in our laboratory discovered that B6-db/db mice do not maintain hyperglycemia if fed a standard mouse diet (5001 chow). In the current study, these mice were given AIN-76A (11.5\% kcal derived from fat) or 5008 chow (17\% kcal derived from fat, a.k.a. breeder chow). After 24 weeks of diabetes, mice fed the AIN-76A diet were only modestly hyperglycemic, despite substantial weight gain; while their GHb levels did reach statistical significance, their final blood glucose levels were not different than the B6- $\mathrm{db}^{+}$controls. These modest changes indicate that the AIN-76A chow was not sufficient to maintain hyperglycemia in these mice. In contrast, the B6-db/db mice fed the 5008 diet had GHb levels twice that of the B6- $\mathrm{db}^{+}$mice and their final blood glucoses were substantially higher than the B6- $\mathrm{db}^{+}$control mice fed the same diet. The last model, the BKS-db/db mice developed substantial hyperglycemia and weight gain when fed the standard 5001 diet.

\section{DN in Models of Type 1 Diabetes}

In the current study, the STZ-treated C57BL/6J did not develop DN, despite significant and prolonged hyperglycemia. There are reports of abnormal sensory function (Obrosova et al., 2005; Gabra et al., 2005; Tam et al., 2004;Christianson et al., 2003b) and NCV (Obrosova et al., 2005) in STZ-treated C57BL/6J mice. Unlike these reported studies, we used 5 low dose STZ injections (versus the more conventional single high dose STZ injection) and DN was assessed at 24 weeks (versus previously published earlier time points, e.g. 12 weeks) to more fully reproduce a time course comparable to human DN. These methodological differences likely underlie the apparent diversity in results between different laboratories. Another important consideration is diet. Our animals were maintained on standard 5001 chow. Essential fatty acid deficiency differentially affects the ability of low dose STZ to induce diabetes in CD-1, BALB/cByJ, DBA/2J and C57BL/6J mice (Wright, Jr. et al., 1995). It may be that maintaining our colony of C57BL/6J mice on the 5001 chow interfered with the development of DN, despite persistent hyperglycemia; it is possible that these animals still produced low doses of insulin, sufficient to ameliorate DN. Unfortunately, most authors do not report the chow used in their studies, making it impossible to fully compare our data with those previously reported (Obrosova et al., 2005;Gabra et al., 2005;Tam et al., 2004; Christianson et al., 2003b).

There are reports of DN in mice made diabetic using the 5 day, low dose STZ injection protocol. Kellogg and Pop-Busui (Kellogg and Pop-Busui, 2005) and Obrosova and colleagues (Obrosova et al., 2005) employed this STZ protocol and detected a 20-25\% decrease in sensory nerve conduction velocities. There are two important differences between their studies and our own. First, less inbred, more mixed background strains of mice were used: 129S7/B6 by Kellogg and Pop-Busui (Kellogg and Pop-Busui, 2005) and 129/SvxC57BL/6J mice by Obrosova and coworkers (Obrosova et al., 2005). Second, in both of these studies the duration of diabetes was shorter ( 6 and 7 weeks respectively). A pivotal study was completed by the Zochodne laboratory (Kennedy and Zochodne, 2005). They followed mice for 9 months after STZ-induced diabetes and reported the presence of DN by behavioral testing, NCV and quantitation of nerve fiber densities. However, unlike the inbred C57BL/6J mice used in our study, these studies used outbred Swiss Wistar mice. Therefore, while the degree of hyperglycemia is comparable in our mice and those 
previously documented (Goss et al., 2002;Kennedy and Zochodne, 2000;Qi et al., 2005), the duration of diabetes and more importantly, substantial strain differences, likely contribute to the observed presence or absence of DN. This idea is further supported by the AMDCC Nephropathy Consortium who found no evidence of diabetic nephropathy in C57BL/6J mice after 6 months of low dose STZ induced diabetes compared to the presence of nephropathy in multiple other strains (Qi et al., 2005). The duration of hyperglycemia should also profoundly affect the development of DN. Beyond the work of Kennedy and Zochodne, (Kennedy and Zochodne, 2005) no comprehensive comparison of DN development over time has been reported. Collectively, our data and that of the AMDCC Nephropathy Consortium support the idea that there are marked strain differences in susceptibility to complications, and that $\mathrm{C} 57 \mathrm{BL} / 6 \mathrm{~J}$ mice are generally more resistant to the microvascular complications of diabetes, despite long term hyperglycemia (Qi et al., 2005).

Heterozygous B6Ins2 $2^{\text {Akita }}$ mice demonstrated minimal signs of DN. At 24 weeks following the onset of diabetes, the B6Ins $2^{\text {Akita }}$ mice display a modest reduction in sensory function and NCV; however, only hind paw latency was significantly decreased $(\mathrm{p}<0.02)$.

Decreased sensory conduction velocities are reported in B6Ins2 ${ }^{\text {Akita }}$ mice at 40 weeks of age by Choeiri and colleagues (Choeiri et al., 2005). There are two major methodological differences between our group and Choeiri (Choeiri et al., 2005); duration of diabetes and the method used to measure sensory NCV. Examination of the B6Ins2 ${ }^{\text {Akita }}$ mice at 24 rather than 40 weeks post onset of diabetes could account for differences in DN detection as this complication may be slow to develop in this model. Symptoms of other diabetic complications do have an early onset in these mice. Diabetic retinopathy (Barber et al., 2005 ) is detected 12 weeks post diabetes onset and polyuria begins shortly after weaning (http://jaxmice.jax.org). Repeated measures of behavior and nerve physiology are needed to clarify the time course and validity of DN in this animal model.

Another factor that may contribute to differences in the detection of DN is the way in which nerve conduction was measured. Choeiri stimulated the nerve every second for $2 \mathrm{~min}$ for a total of 120 stimulations and records the average response (Choeiri et al., 2005). This varies substantially from the AMDCC methods used in the current study (8 to 10 stimulations are averaged) and the 16 stimulations averaged by others (Obrosova et al., 2005;Kennedy and Zochodne, 2005). It is possible that over stimulation of the nerves in the B6Ins2 $2^{\text {Akita }}$ animals results in nerve failure and was perceived as a decrease in conduction velocity (Choeiri et al., 2005). Like the STZ-treated C57BL/6J mice, B6Ins $2^{\text {Akita }}$ mice are also resistant to the development of diabetic nephropathy (Qi et al., 2005), but do develop some findings of diabetic retinopathy (Barber et al., 2005).

\section{DN in Models of Type 2 Diabetes}

Previous work in our laboratory established that when fed standard mouse chow $(5001,12 \%$ $\mathrm{kcal}$ derived from fat), the B6-db/db mice animals revert to euglycemia and in parallel their DN resolves. Interestingly, Kennedy and Zochodne report similar findings in the outbred Swiss Wistar mice i.e. spontaneous recovery of DN with reversion to normal blood glucose levels (Kennedy and Zochodne, 2005). In the current study, we placed B6-db/db mice on one of two different chows; our goal was to identify chow(s) that produced persistent and vigorous hyperglycemia leading to DN. On the AIN-76A chow, the B6-db/db mice were only mildly hyperglycemic. In parallel, these mice developed modest changes in conduction velocity in the tail, but not in the hind limb. This may in part be due to the fact that DN typically affects the longest axons first. More importantly, the absence of DN correlates with the near normal glycemia. In contrast, the B6-db/db mice on the high fat 5008 chow remained strongly hyperglycemic and developed robust DN. 
These data bring to light multiple important concepts. First, the relative resistance of the C57BL/6J mice to the development of $\mathrm{DN}$ is overcome by the $\mathrm{db} / \mathrm{db}$ mutation (but not the B6Ins $2^{\text {Akita }}$, as discussed above). These same data are reported for diabetic nephropathy by the AMDCC Nephropathy Consortium (Qi et al., 2005). Second, the level of hyperglycemia may dictate the development of DN in animals with identical genotypes, in this case the B6$\mathrm{db} / \mathrm{db}$ animals. These data are robustly supported by clinical trials in man, where the degree and duration of hyperglycemia determines the extent and severity of human DN (reviewed in (Jeffcoate, 2004). Finally, special attention must be paid to the content of mouse chow, particularly the fat content. It is well documented that a high fat diet induces hyperglycemia and insulin resistance regardless of the amount of calories derived from simple sugars (Tsunoda et al., 1998;Surwit et al., 1995). In a study of 9 murine genetic backgrounds, West and colleagues report that 6 strains (AKR/J, A/J, C57L/J, C3H/HeJ, DBA/2J, C57BL/6J) develop hyperglycemia and abdominal adiposity when fed a diet containing very high fat (45\% kcal derived from fat)(West et al., 1992). Analysis of the genetic loci responsible for these predispositions is ongoing and includes examining differences between cis and trans acting expression quantitative trait loci (eQTL) and single nucleotide polymorphisms (SNPs) (Watkins et al., 2002;Davis et al., 2005;Doss et al., 2005;Mao et al., 2006). The genetic factors responsible for the observed strain variability are under examination and include differences in glucose transport capability (Rossmeisl et al.,) (Ranheim et al.,), leptin levels (Mehrabian et al.,) and hepatic lipase activity (Mehrabian et al.,). These reports did not examine the long term effects of high fat diets nor did they examine diabetic complications. However, it is clear that metabolic parameters and their genetic substrates must be considered as models of diabetic complications are defined.

The most robust model of DN in the current study was the BKS-db/db mouse. When fed a normal 5001 chow diet, these animals had significant weight gain with persistent hyperglycemia, as previously reported (Norido et al., 1984;Robertson and Sima, 1980). All behavioral and electrophysiological assessments of DN were impaired, with increased thermal latencies in both the tail and hind paw and decreased motor and sensory NCVs. Our data agree with previous reports of DN in this model (Norido et al., 1984;Robertson and Sima, 1980). Similar decreases in nerve function are also reported in the ob/ob mouse, a related genetic model of type 2 diabetes (Drel et al., 2006; Vareniuk et al., 2007).

The ob/ob and $\mathrm{db} / \mathrm{db}$ mutations disrupt hypothalamic leptin signaling and lead to hyperphagia, obesity and insulin resistance. The consensus is that insulin resistance and subsequent hyperglycemia result in diabetic complications including DN. Leptin receptors are localized within the mouse and rat nodose ganglia (Miller et al., 1999) where it is postulated they modulate leptin effects on gastric innervation. Chen et al, 2004 reported the expression and localization of leptin receptors within dorsal root ganglia (DRG) of female Sprague-Dawley rats and its potential regulation by estrogen (Chen et al., 2006). At this point, no intracellular signaling cascade, neurotrophic effect or neurotransmitter function is attributed to leptin in the peripheral nervous system. A study by Matsuada et al, 2004, documented a correlation between TNFa and decreased sensory nerve conduction velocity in human type 2 diabetic patients. Leptin levels were also examined but did not correlate with signs of neuropathy (Matsuda et al., 2004).

Decreased conduction velocities are correlated with decreased myelinated fiber density and changes in axonal caliber in multiple studies of neuropathy including DN (Yagihashi et al., 2001;Robertson and Sima, 1980;Norido et al., 1984) and more recently, changes in IENF (Lauria et al., 2005;Pittenger et al., 2004;Bianchi et al., 2006). Clinically, IENF has all but replaced the use of nerve biopsies for patient diagnosis. For this reason, the third component of the AMDCC phenotyping guidelines is measurement of IENF. IENF provides a rapid, reproducible means to assess end organ innervation and is quantified when other signs of 
$\mathrm{DN}$ are present. In the BKS-db/db mice, the decrease in IENF paralleled the decreases in NCVs and thermal latencies and confirmed an earlier report of decreased IENF in BKS-db/ $\mathrm{db}$ mice (Gibran et al., 2002).

There is a growing consensus driven by both clinical and basic studies that oxidative stress underlies the development of microvascular complications, including DN [reviewed in (Brownlee, 2005; Vinik and Vinik, 2003)]. The AMDCC guidelines suggest that once murine model(s) for DN are established (based on behavioral, electrophysiological and anatomical findings), these potential models should be examined for markers of oxidative stress, including the presence of nitrated proteins and DNA damage (http:// www.amdcc.org). As a first step in adhering to these guidelines, we examined DRG neurons from BKS-db/db after 6 months of diabetes for the suggested markers of oxidative stress. DRG neurons express quantitatively increased levels of nitrated proteins, downstream markers of oxidative stress and a parallel increase in TUNEL stained DRG nuclei, a measure of DNA damage. These data agree with our own previously published reports demonstrating that hyperglycemia induces oxidative stress and activates pathways of DNA damage in sensory neurons (Russell et al., 2002;Vincent et al., 2005). Our findings are also supported by a growing number of studies in outbred STZ-treated mice (Ilnytska et al., 2006) or inbred mouse genetic models of type 2 diabetes (Drel et al., 2006) where there is evidence for increased neural oxidative stress with the onset of DN. Finally, these data also support the proposed idea the BKS-db/db mouse may serve as a good murine model of DN to investigate the therapeutic potential of antioxidant therapy in DN (Ilnytska et al., 2006; Norido et al., 1984;Robertson and Sima, 1980).

In summary, we began our studies with the hypothesis that the level and extent of hyperglycemia would determine the development of DN in different mouse models of type 1 and 2 diabetes. Our results suggest, however, that the genetic background of a mouse is a more important factor than hyperglycemia in the development of DN; the commonly used C57BL/6J inbred mouse was relatively resistant to the development of STZ-mediated DN, despite significant hyperglycemia. In parallel, C57BL/6J animals with the B6Ins2 ${ }^{\text {Akita }}$ mutation also showed few signs of DN, although they remained markedly hyperglycemic. When the $\mathrm{db} / \mathrm{db}$ mutation was bred onto the C57BL/6J background, dietary fat content determined the level of hyperglycemia; those animals on a lower fat diet were nearly euglycemic and developed few signs of DN, while those animals on a higher fat diet had substantial hyperglycemia and met all the AMDCC criteria for an animal model of DN. The most robust model of DN was identified on a different genetic background, C57BKLS. When the $\mathrm{db} / \mathrm{db}$ mutation is placed on the C57BLKS background, these animals develop significant DN over time, with loss of sensory thresholds, slowed NCV, decreased IENF and increased markers of oxidative stress. The BKS-db/db mouse is an appropriate working model of DN in type 2 diabetes and will greatly enhance preclinical testing of potential therapies. Our findings with DN parallel the recent AMDCC reports that genetic background determines if mice will develop diabetic nephropathy, despite high serum and urine glucose levels (Qi et al., 2005;Breyer et al., 2006). Our study indicates that a comprehensive examination of basic chow components combined with background strain is the next logical step in defining optimal animal models of diabetic complications, especially DN.

\section{Acknowledgments}

The authors wish to acknowledge Ms. Julie Erwin for expert manuscript preparation and Drs. Tracy Schwab and Andrea Vincent for expert editorial advice. These studies were conducted within the Morphometry Core of the JDRF Center for the Study of Complications in Diabetes and the Michigan Diabetes Research and Training Center (NIH5P60 DK20572). Grant support: This work was supported by the National Institutes of Health (NS38849, and DK60994), the Juvenile Diabetes Research Foundation Center for the Study of Complications in Diabetes, the 
Office of Research Development (Medical Research Service), and the Program for Neurology Research and Discovery (www.pfund.umich.edu).

\section{References}

Ad Hoc Panel on Endpoints for Diabetic Neuropathy Trials. Positive neuropathic sensory symptoms as endpoints in diabetic neuropathy trials. J Neurol Sci. 2001; 189:3-5. [PubMed: 11596565]

Barber AJ, Antonetti DA, Kern TS, Reiter CE, Soans RS, Krady JK, Levison SW, Gardner TW, Bronson SK. The Ins2Akita mouse as a model of early retinal complications in diabetes. Invest Ophthalmol Vis Sci. 2005; 46:2210-2218. [PubMed: 15914643]

Bianchi R, Brines M, Lauria G, Savino C, Gilardini A, Nicolini G, Rodriguez-Menendez V, Oggioni N, Canta A, Penza P, Lombardi R, Minoia C, Ronchi A, Cerami A, Ghezzi P, Cavaletti G. Protective effect of erythropoietin and its carbamylated derivative in experimental Cisplatin peripheral neurotoxicity. Clin Cancer Res. 2006; 12:2607-2612. [PubMed: 16638873]

Boulton AJ, Vinik AI, Arezzo JC, Bril V, Feldman EL, Freeman R, Malik RA, Maser RE, Sosenko JM, Ziegler D. Diabetic neuropathies: a statement by the American Diabetes Association. Diabetes Care. 2005; 28:956-962. [PubMed: 15793206]

Breyer MD, Qi Z, Tchekneva E. Diabetic nephropathy: leveraging mouse genetics. Curr Opin Nephrol Hypertens. 2006; 15:227-232. [PubMed: 16609287]

Brownlee M. The pathobiology of diabetic complications: a unifying mechanism. Diabetes. 2005; 54:1615-1625. [PubMed: 15919781]

Chen HP, Fan J, Cui S. Detection and estrogen regulation of leptin receptor expression in rat dorsal root ganglion. Histochem Cell Biol. 2006; 126:363-369. [PubMed: 16708246]

Cheng H-L, Sullivan KA, Feldman EL. Immunohistochemical localization of insulin-like growth factor binding protein-5 in the developing rat nervous system. Brain Res Dev Brain Res. 1996; 92:211-218.

Choeiri C, Hewitt K, Durkin J, Simard CJ, Renaud JM, Messier C. Longitudinal evaluation of memory performance and peripheral neuropathy in the Ins2C96Y Akita mice. Behav Brain Res. 2005; 157:31-38. [PubMed: 15617768]

Christianson JA, Riekhof JT, Wright DE. Restorative effects of neurotrophin treatment on diabetesinduced cutaneous axon loss in mice. Exp Neurol. 2003a; 179:188-199. [PubMed: 12618126]

Christianson JA, Ryals JM, McCarson KE, Wright DE. Beneficial actions of neurotrophin treatment on diabetes-induced hypoalgesia in mice. J Pain. 2003b; 4:493-504. [PubMed: 14636817]

Davis RC, Schadt EE, Cervino AC, Peterfy M, Lusis AJ. Ultrafine mapping of SNPs from mouse strains C57BL/6J, DBA/2J, and C57BLKS/J for loci contributing to diabetes and atherosclerosis susceptibility. Diabetes. 2005; 54:1191-1199. [PubMed: 15793261]

Doss S, Schadt EE, Drake TA, Lusis AJ. Cis-acting expression quantitative trait loci in mice. Genome Res. 2005; 15:681-691. [PubMed: 15837804]

Drel VR, Mashtalir N, Ilnytska O, Shin J, Li F, Lyzogubov VV, Obrosova IG. The leptin-deficient (ob/ ob) mouse: a new animal model of peripheral neuropathy of type 2 diabetes and obesity. Diabetes. 2006; 55:3335-3343. [PubMed: 17130477]

Feldman, EL.; Stevens, MJ.; Russell, JW.; Greene, DA. Somatosensory neuropathy. In: Porte, D., Jr; Sherwin, RS.; Baron, A., editors. Ellenberg and Rifkin's Diabetes Mellitus. McGraw Hill; 2003. p. 771-788.

Gabra BH, Merino VF, Bader M, Pesquero JB, Sirois P. Absence of diabetic hyperalgesia in bradykinin B1 receptor-knockout mice. Regul Pept. 2005; 127:245-248. [PubMed: 15680494]

Gibran NS, Jang YC, Isik FF, Greenhalgh DG, Muffley LA, Underwood RA, Usui ML, Larsen J, Smith DG, Bunnett N, Ansel JC, Olerud JE. Diminished neuropeptide levels contribute to the impaired cutaneous healing response associated with diabetes mellitus. J Surg Res. 2002; 108:122-128. [PubMed: 12443724]

Goss JR, Goins WF, Lacomis D, Mata M, Glorioso JC, Fink DJ. Herpes simplex-mediated gene transfer of nerve growth factor protects against peripheral neuropathy in streptozotocin-induced diabetes in the mouse. Diabetes. 2002; 51:2227-2232. [PubMed: 12086954] 
Ilnytska O, Lyzogubov VV, Stevens MJ, Drel VR, Mashtalir N, Pacher P, Yorek MA, Obrosova IG. Poly(ADP-ribose) polymerase inhibition alleviates experimental diabetic sensory neuropathy. Diabetes. 2006; 55:1686-1694. [PubMed: 16731831]

Jeffcoate W. Vascular calcification and osteolysis in diabetic neuropathy-is RANK-L the missing link? Diabetologia. 2004; 47:1488-1492. [PubMed: 15322748]

Kellogg AP, Pop-Busui R. Peripheral nerve dysfunction in experimental diabetes is mediated by cyclooxygenase-2 and oxidative stress. Antioxid Redox Signal. 2005; 7:1521-1529. [PubMed: 16356116]

Kennedy JM, Zochodne DW. The regenerative deficit of peripheral nerves in experimental diabetes: its extent, timing and possible mechanisms. Brain. 2000; 123 (Pt 10):2118-2129. [PubMed: $11004128]$

Kennedy JM, Zochodne DW. Experimental diabetic neuropathy with spontaneous recovery: is there irreparable damage? Diabetes. 2005; 54:830-837. [PubMed: 15734862]

Lauria G, Lombardi R, Borgna M, Penza P, Bianchi R, Savino C, Canta A, Nicolini G, Marmiroli P, Cavaletti G. Intraepidermal nerve fiber density in rat foot pad: neuropathologic-neurophysiologic correlation. J Peripher Nerv Syst. 2005; 10:202-208. [PubMed: 15958131]

Layton BE, Sastry AM, Wang H, Sullivan KA, Feldman EL, Komorowski TE, Philbert MA. Differences between collagen morphologies, properties and distribution in diabetic and normal BioBreeding and Sprague-Dawley rat sciatic nerves. Journal of Biomechanics. 2004; 37:879-888. [PubMed: 15111075]

Lee JH, Cox DJ, Mook DG, McCarty RC. Effect of hyperglycemia on pain threshold in alloxandiabetic rats. Pain. 1990; 40:105-107. [PubMed: 2339005]

Leiter EH, Coleman DL, Eisenstein AB, Strack I. Dietary control of pathogenesis in C57BL/KsJ db/db diabetes mice. Metabolism. 1981; 30:554-562. [PubMed: 7015072]

Mao HZ, Roussos ET, Peterfy M. Genetic analysis of the diabetes-prone C57BLKS/J mouse strain reveals genetic contribution from multiple strains. Biochim Biophys Acta. 2006; 1762:440-446. [PubMed: 16481151]

Matsuda M, Kawasaki F, Inoue H, Kanda Y, Yamada K, Harada Y, Saito M, Eto M, Matsuki M, Kaku K. Possible contribution of adipocytokines on diabetic neuropathy. Diabetes Res Clin Pract. 2004; 66(Suppl 1):S121-3. S121-S123. [PubMed: 15563961]

Mehrabian M, Wen PZ, Fisler J, Davis RC, Lusis AJ. Genetic loci controlling body fat, lipoprotein metabolism, and insulin levels in a multifactorial mouse model.

Miller SM, Schmalz PF, Benarroch EE, Szurszewski JH. Leptin receptor immunoreactivity in sympathetic prevertebral ganglion neurons of mouse and rat. Neurosci Lett. 1999; 265:75-78. [PubMed: 10327172]

Norido F, Canella R, Zanoni R, Gorio A. Development of diabetic neuropathy in the C57BL/Ks (db/ db) mouse and its treatment with gangliosides. Exp Neurol. 1984; 83:221-232. [PubMed: 6692864]

Obrosova IG, Mabley JG, Zsengeller Z, Charniauskaya T, Abatan OI, Groves JT, Szabo C. Role for nitrosative stress in diabetic neuropathy: evidence from studies with a peroxynitrite decomposition catalyst. FASEB J. 2005; 19:401-403. [PubMed: 15611153]

Pittenger GL, Ray M, Burcus NI, McNulty P, Basta B, Vinik AI. Intraepidermal nerve fibers are indicators of small-fiber neuropathy in both diabetic and nondiabetic patients. Diabetes Care. 2004; 27:1974-1979. [PubMed: 15277426]

Polydefkis M, Haue P, Griffin J, McArthur JC. Skin biopsy as a tool to assess distal small fiber innervation in diabetic neuropathy. Diabetes Technology and Therapeutics. 2001; 3:23-28. [PubMed: 11469706]

Qi Z, Fujita H, Jin J, Davis LS, Wang Y, Fogo AB, Breyer MD. Characterization of susceptibility of inbred mouse strains to diabetic nephropathy. Diabetes. 2005; 54:2628-2637. [PubMed: 16123351]

Ranheim T, Dumke C, Schueler KL, Cartee GD, Attie AD. Interaction between BTBR and C57BL/6J genomes produces an insulin resistance syndrome in (BTBR x C57BL/6J) F1 mice.

Robertson DM, Sima AAF. Diabetic neuropathy in the mutant mouse [C57/BL/Ks(db/db)]: a morphometric study. Diabetes. 1980; 29:60-67. [PubMed: 6991317] 
Rossmeisl M, Rim JS, Koza RA, Kozak LP. Variation in type 2 diabetes--related traits in mouse strains susceptible to diet-induced obesity.

Russell JW, Feldman EL. Insulin-like growth factor-I prevents apoptosis in sympathetic neurons exposed to high glucose. Horm Metab Res. 1999; 31:90-96. [PubMed: 10226787]

Russell JW, Golovoy D, Vincent AM, Mahendru P, Olzmann JA, Mentzer A, Feldman EL. High glucose induced oxidative stress and mitochondrial dysfunction in neurons. FASEB J. 2002; 16:1738-1748. [PubMed: 12409316]

Russell JW, Sullivan KA, Windebank AJ, Herrmann DN, Feldman EL. Neurons undergo apoptosis in animal and cell culture models of diabetes. Neurobiol Dis. 1999; 6:347-363. [PubMed: 10527803]

Stevens MJ, Dananberg J, Feldman EL, Lattimer SA, Kamijo M, Thomas TP, Shindo H, Sima AAF, Greene DA. The linked roles of nitric oxide, aldose reductase and $\left(\mathrm{Na}^{+}, \mathrm{K}^{+}\right)$-ATPase in the slowing of nerve conduction in the streptozotocin diabetic rat. J Clin Invest. 1994; 94:853-859. [PubMed: 8040341]

Stevens MJ, Lattimer SA, Feldman EL, Helton ED, Millington DS, Sima AAF, Greene DA. Acetyl-Lcarnitine deficiency as a cause of altered nerve myo-Inositol content, $\mathrm{Na}$, K-ATPase activity and motor conduction velocity in the streptozotocin-diabetic rat. Metabolism. 1996; 45:865-872. [PubMed: 8692023]

Sullivan KA, Castle VP, Hanash SM, Feldman EL. Insulin-like growth factor II in the pathogenesis of human neuroblastoma. Am J Pathol. 1995; 147:1790-1798. [PubMed: 7495303]

Surwit RS, Feinglos MN, Rodin J, Sutherland A, Petro AE, Opara EC, Kuhn CM, Rebuffe-Scrive M. Differential effects of fat and sucrose on the development of obesity and diabetes in C57BL/6J and A/J mice. Metabolism. 1995; 44:645-651. [PubMed: 7752914]

Tam J, Rosenberg L, Maysinger D. INGAP peptide improves nerve function and enhances regeneration in streptozotocin-induced diabetic C57BL/6 mice. FASEB J. 2004; 18:1767-1769. [PubMed: 15345684]

Tsunoda N, Ikemoto S, Takahashi M, Maruyama K, Watanabe H, Goto N, Ezaki O. Highmonounsaturated fat diet-induced obesity and diabetes in C57BL/6J mice. Metabolism. 1998; 47:724-730. [PubMed: 9627373]

Vareniuk I, Pavlov IA, Drel VR, Lyzogubov VV, Ilnytska O, Bell SR, Tibrewala J, Groves JT, Obrosova IG. Nitrosative stress and peripheral diabetic neuropathy in leptin-deficient (ob/ob) mice. Exp Neurol. 2007; 205:425-436. [PubMed: 17475250]

Vincent AM, Feldman EL. New insights into the mechanisms of diabetic neuropathy. Rev Endo Metabol Dis. 2004; 5:227-236.

Vincent AM, McLean LL, Backus C, Feldman EL. Short-term hyperglycemia produces oxidative damage and apoptosis in neurons. FASEB J. 2005; 19:638-640. [PubMed: 15677696]

Vinik AI, Vinik E. Prevention of the complications of diabetes. Am J Manag Care. 2003; 9:S63-S80. [PubMed: 12653455]

Watkins SM, Reifsnyder PR, Pan HJ, German JB, Leiter EH. Lipid metabolome-wide effects of the PPARgamma agonist rosiglitazone. J Lipid Res. 2002; 43:1809-1817. [PubMed: 12401879]

West DB, Boozer CN, Moody DL, Atkinson RL. Dietary obesity in nine inbred mouse strains. Am J Physiol. 1992; 262:R1025-R1032. [PubMed: 1621856]

Wright JR Jr, Fraser RB, Kapoor S, Cook HW. Essential fatty acid deficiency prevents multiple lowdose streptozotocin-induced diabetes in naive and cyclosporin-treated low-responder murine strains. Acta Diabetol. 1995; 32:125-130. [PubMed: 7579534]

Yagihashi S, Yamagishi SI, Wada RR, Baba M, Hohman TC, Yabe-Nishimura C, Kokai Y. Neuropathy in diabetic mice overexpressing human aldose reductase and effects of aldose reductase inhibitor. Brain. 2001; 124:2448-2458. [PubMed: 11701599]

Yoshioka M, Kayo T, Ikeda T, Koizumi A. A novel locus, Mody4, distal to D7Mit189 on chromosome 7 determines early-onset NIDDM in nonobese C57BL/6 (Akita) mutant mice. Diabetes. 1997; 46:887-894. [PubMed: 9133560] 


\section{ABBREVIATIONS}

$\begin{array}{ll}\text { AMDCC } & \text { Animal Models of Diabetic Complications Consortium } \\ \text { DRG } & \text { Dorsal root ganglia } \\ \text { DN } & \text { Diabetic neuropathy } \\ \text { GHb } & \text { Glycated hemoglobin } \\ \text { IENF } & \text { Intraepidermal nerve fiber } \\ \text { IHC } & \text { Immunohistochemistry } \\ \text { NCV } & \text { Nerve conduction velocity } \\ \text { NT } & \text { Nitrotyrosine } \\ \text { PGP9.5 } & \text { protein gene product 9.5, ubiquitin C-terminal hydrolase } \\ \text { PLP } & \text { Paraformaldehyde, lysine and sodium periodate } \\ \text { SMNCV } & \text { Sciatic-tibial motor nerve conduction velocity } \\ \text { STZ } & \text { Streptozotocin } \\ \text { TDML } & \text { Tail motor distal latency } \\ \text { TSNCV } & \text { Tail sensory nerve conduction velocity } \\ \text { TUNEL } & \text { TdT mediated dUTP-biotin nick end labeling }\end{array}$


A

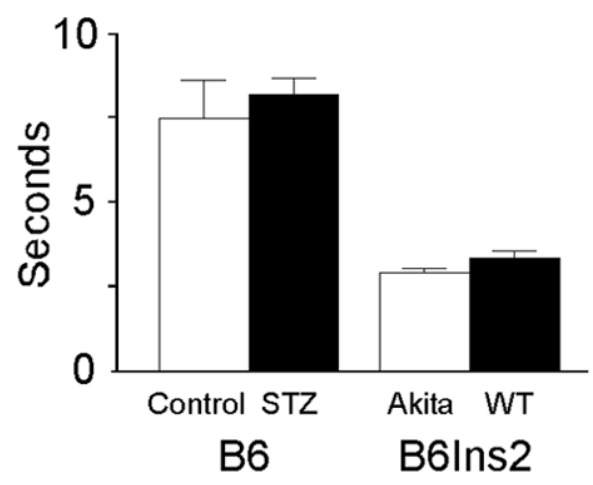

C

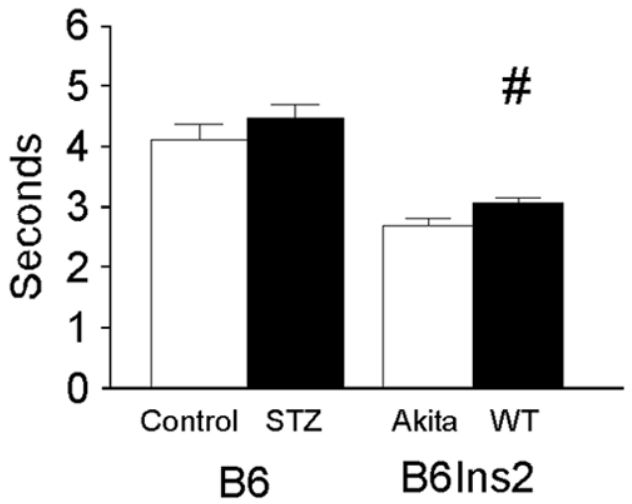

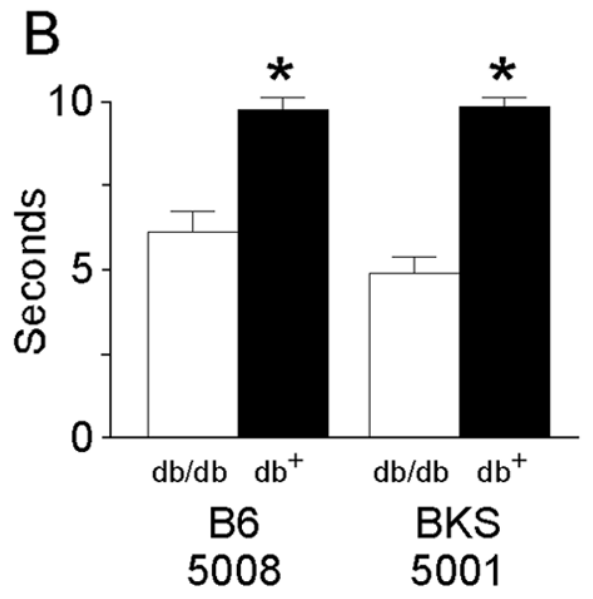

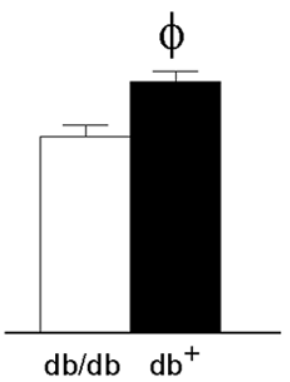

B6

5008

Fig. 1.

Response time to a thermal stimulus, measured in seconds, is used to assess sensory function in the tail and hind paw of nondiabetic and diabetic mice. A) STZ-treated B6 (Control $n=5$, $\mathrm{STZ} n=9)$ and B6Ins $2^{\text {Akita }}$ mice $\left(\right.$ B6Ins $2^{\text {WT }} \mathrm{n}=5$, B6Ins $2^{\text {Akita }}$ 9) were placed in an acrylic holder atop a tail flick analgesia meter (Model 336TG Life Sciences, Woodland Hills, CA). The time from activation of the beam to animal response was recorded electronically(Lee et al., 1990). B) Tail flick was measured in B6-db/db on a high fat diet (5008) (nondiabetic = 12 , diabetic $=9)$ and BKS-db/db (nondiabetic $=13$, diabetic $n=12)$ as in $(A)(* p<0.001)$. C) STZ-treated B6 (Control $n=8, S T Z n=7)$, B6Ins $2^{\text {Akita }}$ mice (B6Ins $2^{\mathrm{WT}} \mathrm{n}=5$, B6Ins $2^{\text {Akita }} \mathrm{n}=8$ ) and the B6-db/db mice fed the 5008 chow (nondiabetic $\mathrm{n}=10$, diabetic $\mathrm{n}=10$ ) were placed in compartments on a warm $\left(32^{\circ} \mathrm{C}\right)$ glass plate (Model 336TG Life Sciences, Woodland Hills, CA). Using an attached mirror, the same light source was maneuvered beneath the hind paw and the time of activation of the beam to the time of paw withdrawal was recorded (Lee et al., 1990). \#p<0.02 and $\varphi \mathrm{p}<0.002$ when comparing nondiabetic to diabetic sensory thresholds. Open bars represent the nondiabetic measurements and the black bars represent the diabetic measurements. 
A

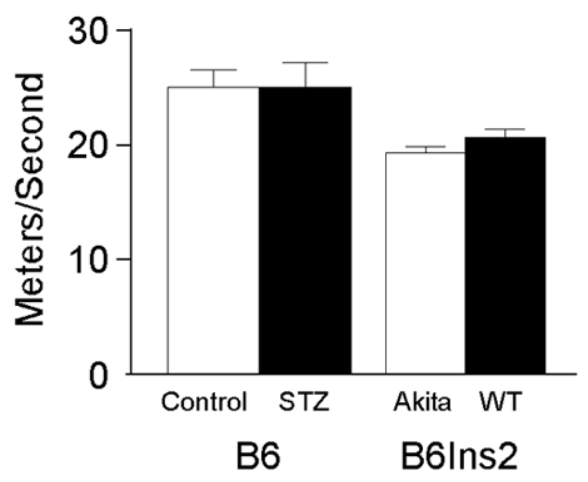

B

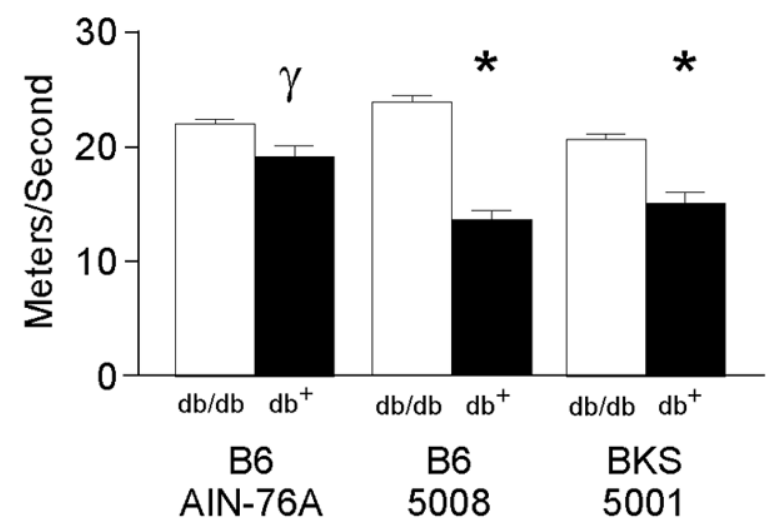

Fig. 2.

Tail sensory nerve conduction velocity (TSNCV) measured in meters per second was quantified in type 1 and type 2 diabetic mice. A) TSNCV was performed as described in the Methods on STZ-treated B6 (Control $\mathrm{n}=8, \mathrm{STZ} \mathrm{n}=8$ ) and B6Ins2 ${ }^{\text {Akita }}$ mice (B6Ins2 ${ }^{\mathrm{WT}} \mathrm{n}$ $=8$, B6Ins $2^{\text {Akita }} \mathrm{n}=10$ ). B) TSNCV was performed as in (A) on models of type 2 diabetes, B6-db/db on both the AIN-76A (nondiabetic $\mathrm{n}=5$, diabetic $\mathrm{n}=7$ ) and 5008 (nondiabetic $\mathrm{n}$ $=10$, diabetic $n=5$ ) diets and BKS-db/db (nondiabetic $n=13$, diabetic $n=11$ ) $\gamma \mathrm{p}<0.01$ and ${ }^{*} \mathrm{p}<0.001$ when comparing nondiabetic to diabetic sensory thresholds. Open bars represent the nondiabetic measurements and the black bars represent the diabetic measurements. 

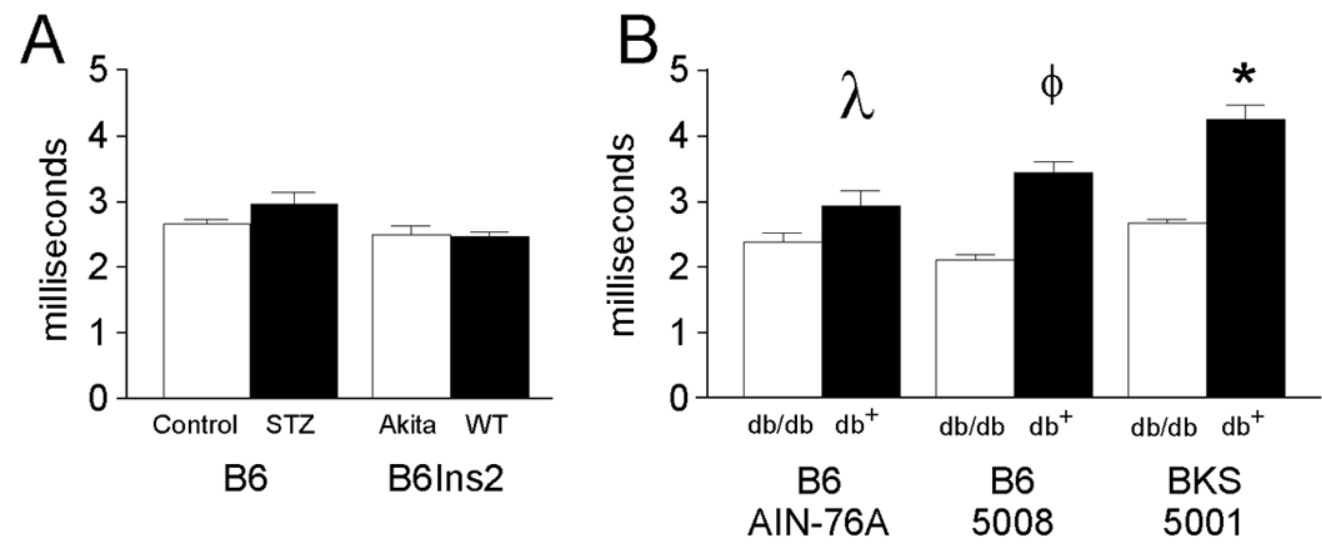

Fig. 3.

Near nerve distal motor latencies measured in milliseconds were assessed in the tail of both type 1 and type 2 diabetic mice. A) Tail distal motor latency (TDML) was performed as described in the Methods in STZ-treated B6 (Control $n=8, S T Z n=9)$ and B6Ins2 ${ }^{\text {Akita }}$ mice (B6Ins $2^{\text {WT }} \mathrm{n}=6$, B6Ins $2^{\text {Akita }} \mathrm{n}=10$ ) compared to nondiabetic mice. B) TDML was performed as in (A) in B6-db/db mice fed either the AIN-76A diet (nondiabetic $\mathrm{n}=5$, diabetic $\mathrm{n}=8$ ) or the 5008 diet (nondiabetic $\mathrm{n}=10$, diabetic $\mathrm{n}=6$ ) and BKS-db/db (nondiabetic $\mathrm{n}=13$, diabetic $\mathrm{n}=13$ ). ${ }^{*} \mathrm{p}<0.001, \varphi \mathrm{p}<0.002, \lambda \mathrm{p}<0.05$ when comparing nondiabetic to diabetic distal motor latency. Open bars represent the nondiabetic measurements and the black bars represent the diabetic measurements. 

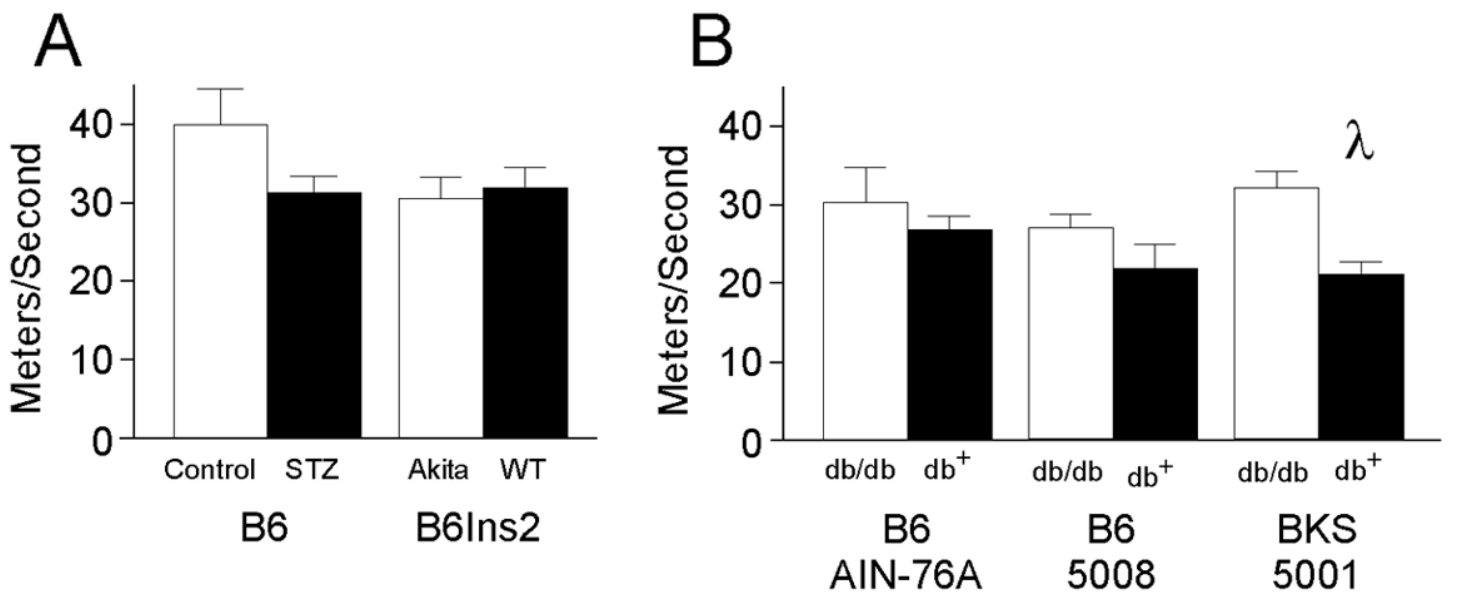

Fig. 4.

Motor nerve conduction velocity measured in meters per second was quantified in the left sciatic nerve of type 1 and type 2 diabetic mice. A) Sciatic motor nerve conduction velocity (SMNCV) was quantified as described in the Methods in STZ-treated B6 (Control $\mathrm{n}=5$, STZ $n=4)$ and B6Ins $2^{\text {Akita }}$ mice $\left(B 6 I n s 2^{\text {WT }} n=6\right.$, B6Ins $\left.2^{\text {Akita }} n=8\right)$. B) SMNCV was performed as in (A) in the B6-db/db mice fed the AIN-76A diet (nondiabetic $n=4$, diabetic $\mathrm{n}=8$ ) or the 5008 diet (nondiabetic $\mathrm{n}=10$, diabetic $\mathrm{n}=5$ ). SMNCV was significantly decreased in the BKS-db/db mice (nondiabetic $n=11$, diabetic $n=10$ ). $\lambda p<0.05$ comparing nondiabetic to diabetic SMNCV. Open bars represent the nondiabetic measurements and the black bars represent the diabetic measurements. 

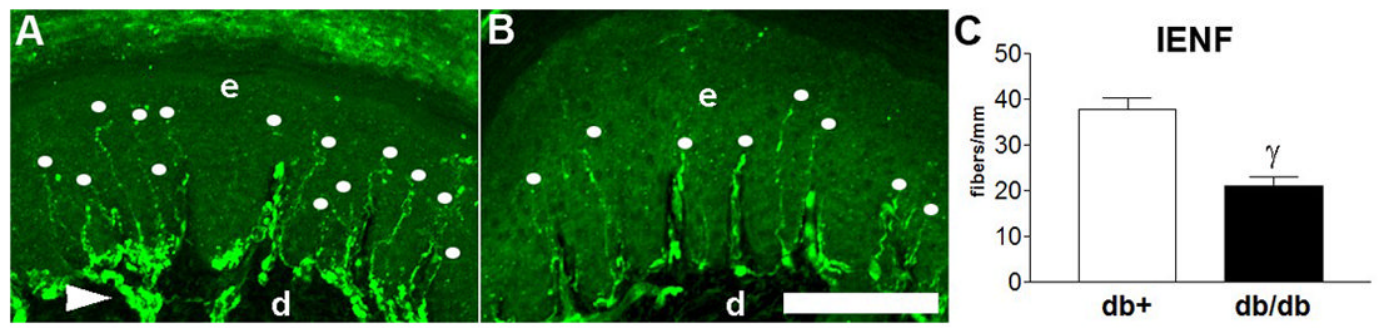

Fig. 5.

IENF measures functional innervation of the skin. A) PGP9.5 immunofluorescence within a nondiabetic $(\mathrm{n}=5) \mathrm{BKS}-\mathrm{db}^{+}$foot pad demonstrating a normal pattern of innervation (dots). B) PGP9.5 immunofluorescence within a diabetic $(\mathrm{n}=5) \mathrm{BKS}-\mathrm{db} / \mathrm{db}$ foot pad demonstrating a decrease in the number of fibers (dots). C) Quantitation of IENF is presented as the number of fibers/linear $\mathrm{mm}$ of epidermis. $\mathrm{d}=$ dermis, $\mathrm{e}=$ epidermis, dots $=$ intraepidermal nerve fiber, arrowhead $=$ dermal fiber bundles. $\gamma p>0.01$. Bar $=100 \mu \mathrm{m}$. Open bars represent the nondiabetic measurements and the black bars represent the diabetic measurements. 

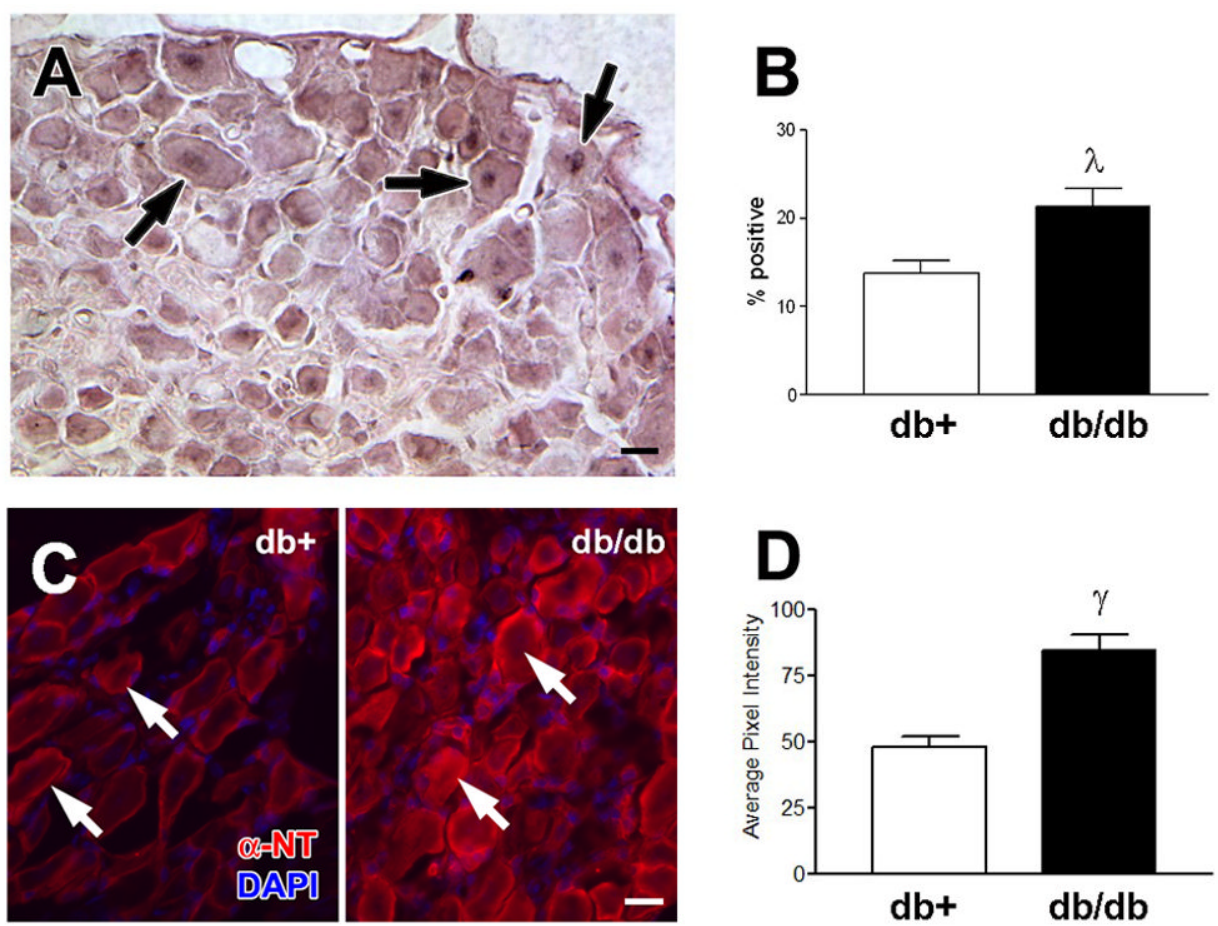

Fig. 6.

Damaged DNA was measured by TUNEL staining. A) TUNEL positive sensory neurons (arrows) were detected in the lumbar DRG of BKS-db/db. B) Increased number of TUNEL labeled DRG in BKS-db/db mice at 24 weeks, $\lambda p<0.05$. Five animals per group and $>150$ neurons per animal were counted. Results are expressed as the percent TUNEL positive cells of total neurons counted. Localization of nitrated proteins was measured by nitrotyrosine immunofluorescence (NT-immunofluorescence). C) NT-immunofluorescence reveals an increase in nitrated proteins within DRG neurons (arrows) from BKS-db/db compared to $\mathrm{BKS}-\mathrm{db}^{+}$mice [nuclei stained with DAPI]. D) Histograms of the fluorescence signal indicate a relative increase in the intensity of NT-immunofluorescence in DRG from BKS$\mathrm{db}^{+}$versus BKS-db/db mice $(\gamma \mathrm{p}<0.01)$. Bar $=20 \mu \mathrm{m}$. Open bars represent the nondiabetic measurements and the black bars represent the diabetic measurements. 


\section{Table 1}

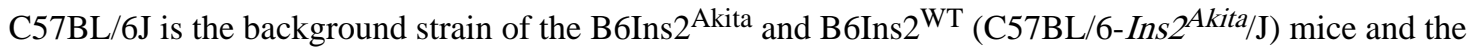
B6.Cg-m Lepr ${ }^{d b} /++/$ J mice. C57BLKS/J (Jax Stock Number 000662) is background strain for the BKS.Cg- $m$ $+/+\operatorname{Lepr}^{d b} / \mathrm{J}$ mice.

\begin{tabular}{|l|l|l|l|l|}
\hline \multicolumn{2}{|l|}{ Common Name } & Type of Diabetes & Strain Name & Jax Stock Number \\
\hline $\begin{array}{l}\text { B6 STZ } \\
\text { B6 }\end{array}$ & $\begin{array}{l}\text { Diabetic } \\
\text { Nondiabetic }\end{array}$ & type 1, induced with low dose STZ & C57BL/6J & 000664 \\
\hline $\begin{array}{l}\text { B6Ins2 } 2^{\text {Akita }} \\
\text { B6Ins2 }\end{array}$ & $\begin{array}{l}\text { Diabetic } \\
\text { Nondiabetic }\end{array}$ & type 1, spontaneous & C57BL/6-Ins2 $2^{\text {Akita } / \mathrm{J}}$ & 003548 \\
\hline $\begin{array}{l}\text { B6-db/db } \\
\text { B6-db }\end{array}$ & $\begin{array}{l}\text { Diabetic } \\
\text { Nondiabetic }\end{array}$ & type 2, spontaneous, diet dependent & B6.Cg- $m$ Lept L $^{\text {db } /++/ J}$ & 000699 \\
\hline $\begin{array}{l}\text { BKS-db/db } \\
\text { BKS-db }\end{array}$ & $\begin{array}{l}\text { Diabetic } \\
\text { Nondiabetic }\end{array}$ & type 2, spontaneous & BKS.Cg- $m+/+L e p I^{d b / J}$ & 000642 \\
\hline
\end{tabular}




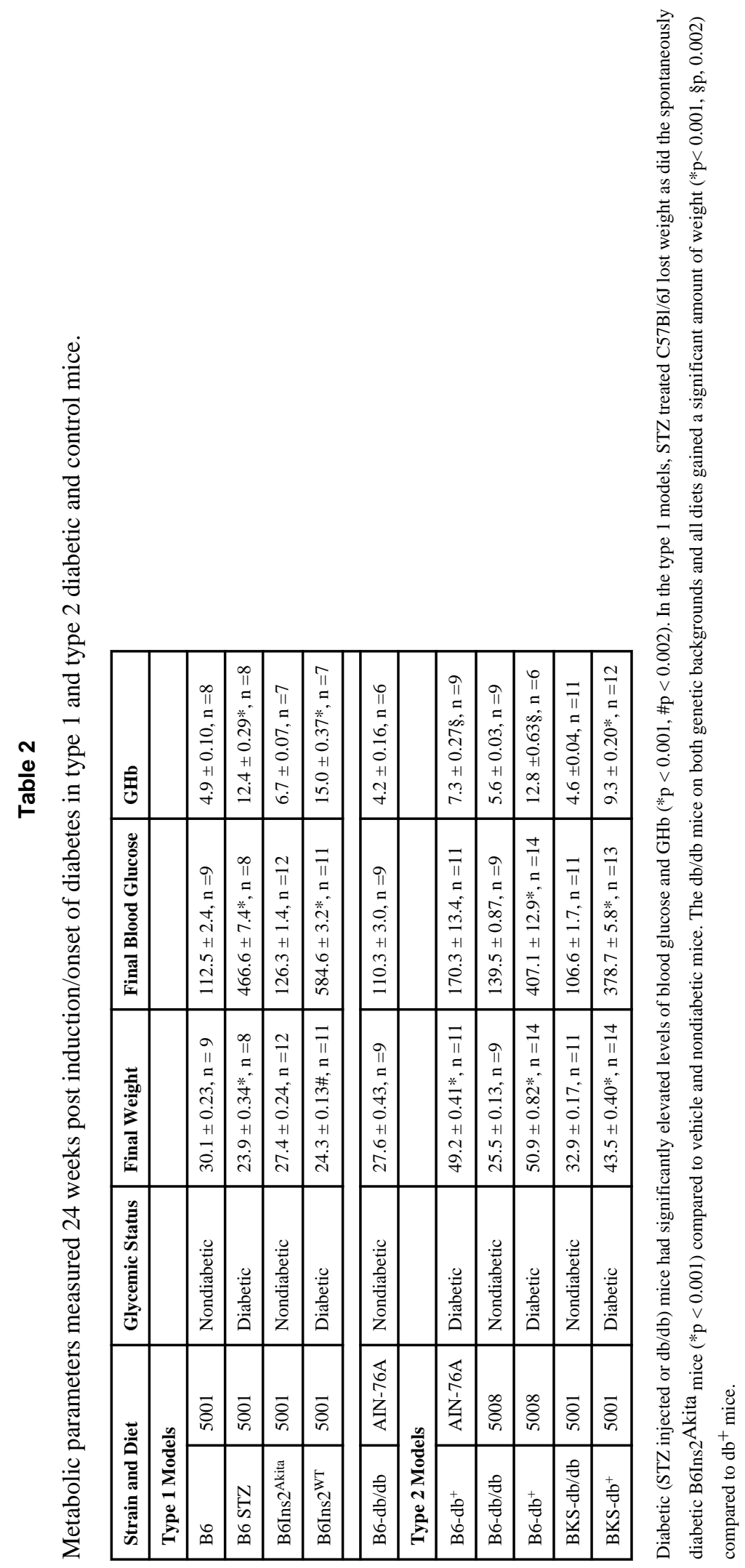

Neurobiol Dis. Author manuscript; available in PMC 2013 August 01. 